\title{
FUNÇÃO DA EDUCAÇÃO FÍSICA ESCOLAR
}

\section{Carmem Lácia SOARES*}

Como sou muito indisciplinada, escrevi um texto e vou pedir licença para lê-lo uma vez que se eu não o fizesse certamente extrapolaria o tempo, vou proceder a esta leitura e em seguida vamos poder debater. Antes de iniciar lembraria que este é um texto de revisão, é um texto para debate e certamente será bastante enriquecido após as nossas discussões. O tema da mesa é "Função da Educação Física Escolar". A nossa exposição sobre esse tema está dividida em três momentos os quais procuramos apresentar de modo articulado.

Assim, num primeiro momento, faremos referência ao termo FUNÇÃo a partir da teoria funcionalista, na qual o termo em questão é empregado na esfera das instituições.

Num segundo momento, faremos referência ao significado do termo PAPEL, empregado na esfera dos indivíduos, e básico para o entendimento das "funções", as quais só serão plenamente desempenhadas se os sujeitos concretos da relação pedagógica - professor e o aluno - incorporarem o papel que lhes foi destinado em sua prática social.

Num terceiro e último momento, procuraremos apontar alguns caminhos para a Educação Física Escolar, caminhos estes que acreditamos, apenas começam a ser esboçados.

\section{O TERMO "FUNÇÃO"}

Como já afirmamos, o termo FUNÇĀO, a partir de uma abordagem estrutural-funcionalista atribuído às instituições. É um termo retirado das ciências biológicas e introduzido nas ciências sociais. Há indicações de que o conceito de função tenha sido introduzido no âmbito das ciências sociais por $\mathbf{H}$. Spencer, que para tal partiu, basicamente, da Fisiologia.

O termo função pode ser definido como

...una condicion, un estado de cosas, resultante de la operación (incluyendo en el término "operación" la mera persistencia) de acuerdo con una(s) estructura(s), de una unidade del tipo considerado. En el caso de las ciências biológicas tal unidade es, por lo general, un organismo o un subsistema de un organismo. En el caso de las ciências sociales, la unidad es, por lo general, un sistema de accion que entrana una persona o un conjunto de personas (actores).

Alguns antropólogos como R. Brown $(1936,1935)$, adeptos do método estrutural- funcionalista, afirmam ser função uma contribuição particular para a existência e a perpetuação de um dado sistema mais geral. ${ }^{2}$

Esta interpretação dada ao termo teve como precursor o sociólogo francês E. Durkheim, que definiu...."como função de uma instituição social, a correspondência entre ela e as necessidades... do organismo social". ${ }^{3}$

Para os sociólogos funcionalistas, o termo função inclui ações sociais, processos em andamento, estruturas de grupo e até fenômenos não padronizados culturalmente.

\footnotetext{
* Faculdade de Educação da Universidade Estadual de Campinas.
} 
Talcott Parsons, sociólogo e teórico do funcionalismo, considera importantíssimo o conceito de função, afirmando que

...seu papel crucial $€$ fornecer critérios da importância de fatores e processos dinâmicos dentro do sistema... ou um processo ou conjunto de condições "contribui" para a manutenção (ou desenvolvimento) do sistema, ou é "disfuncional" no sentido de que prejudica a integração, eficácia, etc. do sistema.

O conceito de função constitui-se num conceito chave para a teoria estrutural funcionalista, tendo sido aprimorado de tal modo que é possível fazer ...distinções entre conseqüências intencionais e reconhecidas pelos participantes do sistema (funções manifestas) e as que não são nem intencionais nem reconhecidas (funções latentes). 5

Portanto a partir desta abordagem, a função é a parte que contribui para a manutenção, conservação e perpetuação de um todo que podemos denominar de sistema, e que torna assim possível a sua funcionalidade.

Parece consensual para os entendimentos hegemônicos das funções a serem desempenhadas pela Educação Física Escolar, uma certa instrumentalização de seus conteudos, e neste sentido uma interpretação "funcional" de sua prática pedagógica.

A legislação específica ${ }^{6}$, a produção do conhecimento e a prática pedagógica, parecem apontar, ainda nos dias atuais, para uma visão "biológica" da Educação Física Escolar, na qual sua função volta-se para a melhoria da aptidão física dos indivíduos. Para esta compreensão sobre a função da Educação Física Escolar, a melhoria da aptidão física dos indivíduos, mecanicamente, estaria contribuindo para o desenvolvimento social, uma vez que os..."indivíduos estariam mais aptos a atuar na sociedade e, portanto, seriam também mais 'úteis' a ela.". 7

Para esta visão, é ainda função da Educação Física Escolar, o desenvolvimento, aprimoramento e manutenção da saúde, numa clara alusão à saúde física e não como saúde social. $O$ exercício físico é então considerado "em si", como fator de desenvolvimento da saúde numa relação de causa e efeito. Esta compreensão vai de encontro com aquela formulada pela Organização Mundial de Saúde, na qual a saúde só pode ser compreendida como resultado de condições dignas de vida, o que certamente não ocorre com a maioria da população brasileira.

Somada a esta visão, há uma outra que foi denominada por Bracht ${ }^{8}$ de "bio-psicológica", e que incorporando a visão anterior (biológica), postula como função da Educação Física Escolar

...a melhoria da aptidão física (dos indivíduos), o seu desenvolvimento intelectual e a manutenção do equilíbrio afetivo-emocional. Valendo-se de uma abordagem sistệmica, poderíąmos afirmar que a Educação Física atua sobre os domínios psicomotor, cognitivo e afetivo.

Embora muitos escritos (teoria) e até mesmo a legislação proclamem esta "integração" do homem dividido, quando teoria e prática se unem, ou seja, na ação, é possível perceber, desde os cursos de formação de profissionais de Educação Física (que ainda exigem até os dias de hoje um teste físico para ingressar num curso de Educação Física) até as escolas de 10. e 20. graus, a consideração de valores de ordem física e um certo menosprezo e secundarização daqueles de ordem psicossocial. Espera-se que os efeitos ditos "positivos" ocorram por uma mecânica relação de causa e efeito do exercício físico em si.

Para as duas visões apontadas, a relação da Educação Física com o contexto social, nele inclusa a instituição escolar é uma relação funcionalista. Cabe à Educação Física Escolar contribuir enquanto parte (função particular do sistema), na formação de um cidadão física e psiquicamente apto a desempenhar um determinado papel a ele atribuído na prática social, de acordo com a estrutura vigente, no sentido de mantê-la em seu estado atual.

\section{O "PAPEL" DOS PAPÉIS SOCIAIS}

Para darmos conta do entendimento do desenvolvimento pleno das funções a serem desempenhadas pela Educação Física no interior da instituição escolar, torna-se necessário determo-nos 
ainda que de forma superficial, nos "papéis" que foram atribuídos aos sujeitos concretos da relação pedagógica escolar - professor e o aluno - para o pleno desenvolvimento das funções aqui registradas.

Para falar sobre papel, cabe-nos precisar este termo utilizado na teoria funcionalista em referência aos indivíduos.

Talcott Parsons nos diz que papel ...é a participação estruturada, ou seja, regulada por normas, de uma pessoa num processo concreto de interação social com outros titulares de papéis concretos e especificados. 10

Numa situação social, portanto, os sujeitos sociais são considerados como atores numa peça teatral, desempenhando PAPÉIS e estando assim sujeitos a regras e possuindo deveres e obrigações que podem ser sancionados segundo sua maior ou menor eficácia ao executá-los.

Analisando o "papel" do supervisor educacional, em estudos realizados em 1983, a Profa. S.F. Correa da Silva da UFPr assim se expressa sobre esta seqüência de práticas estruturadas e reconhecidas que denominam "papel". A partir de uma abordagem funcionalista,

...um papel é compreendido como uma cristalização de uma relação de forças, tendo como efeito o reconhecimento de que uma seqüência de práticas deve ser estruturada de uma certa maneira e não de outra. É o conjunto de competências necessárias ao desempenho de determinado papel. A cristalização de uma relação de forças em um papel evita, assim, que os parceiros que estão em relação tenham uma confrontação, cuja saída, sendo previsível, a torna desnecessária. Assim compreendido, um papel é um ritual e tem, portanto, um duplo efeito: por um lado, os adversários reconhecem que a atual relaçẩo de forças é uma "específica" e não outră e, por outro lado, a dominação de um dos adversários pelo outro exerce-se plenamente.

Ou seja, há, a partir deste entendimento de papel social, a certeza de que as relações de força e conseqüentemente de poder e dominação são estáticas, previsíveis e sem conflitos ou contradições.

Reconhecendo portanto, a existência de uma dada correlação de forças, têm-se as condições dadas da institucionalização do papel, cujo efeito predominante, conforme observa T. Parsons, ${ }^{12}$ "...é a dominação exercida por um dos parceiros sobre o outro."

Este entendimento de papel, largamente utilizado na Educação em geral e na Educação Física em particular, é justificado pela necessidade da "ordem", da "disciplina" a partir de normas e sanções, e associado à idéia de que a escola só deve trabalhar com aquilo que é útil, funcional e adequado ao sistema, ou seja, com aquilo que contribui para a realização de um fim padronizado e normatizado.

Consideramos necessário e oportuno refletir um pouco sobre o empobrecimento das relações sociais e de suas práticas, entre elas a prática pedagógica escolar, quando estas se dão nos parâmetros daquilo que é útil, funcional e instrumental, o que nos parece, tem sido historicamente o caso da Educação Física Escolar.

Para tal, torna-se importante fazermos referência a todo um processo cultural existente na sociedade ocidental desde o final do século XIX que acaba legitimando uma "cultura utilitária", ou como diz A. Gouldner..."uma cultura que instrumentaliza as práticas sociais, educando os sujeitos para ocuparem PAPÉIS na sociedade sendo assim úteis." ${ }^{13}$

A cultura utilitária que Gouldner faz referência, é aquela criada e elaborada pela classe média que ao longo de todo século XVIII foi tolerada pelo clero e pela aristocracia pela sua utilidade.

No desenvolvimento histórico da sociedade ocidental, a classe média, com sua utilidade, de tolerada simplesmente, passa a ser respeitada e, desse modo, transforma NORMAS e PADRÕES.

Segundo as análises desenvolvidas por Gouldner, durante o século XIX, a classe média, valendose do seu critério de utilidade, impôs certas exigências. No que diz respeito às recompensas distribuídas na sociedade, a classe média vai exigir que estas sejam dadas somente para quem possui talento e energia manifestada individualmente, enfim, para aqueles que demonstrassem esforço individual para conseguir um espaço na sociedade, e não mais sobre a base do nascimento e da identidade social. ${ }^{14}$

Qual a razão de fazermos referência a estas informações e, em especial, ao conceito de cultura utilitária?

Porque a Educação Física, que nasce no final do século XIX com os filósofos, pedagogos e médicos, é fruto desta cultura utilitária. 
Ela tem como função normatizar, disciplinar e uniformizar os corpos e as mentes. A sua função "educativa" no âmbito escolar, foi e tem sido, hegemonicamente, aquela de reforçar os papéis sociais exigidos para a manutenção do sistema, instrumentalizando os movimentos para as tarefas "essências" na escola.

\section{O "PAPEl" dos Sujeitos concretos da RElaÇão pedagógica escolar - o PROFESSOR E O ALUNO}

Para o desempenho das funções apontadas como ainda hegemônica na Educação Física Escolar, há que fazermos referência ao papel atribuído ao professor e ao aluno no ambiente escolar.

Quanto ao papel do professor de Educação Física na instituição escolar, vemos que lhe É atribuído desde o papel do militar, incorporado na figura do "instrutor" nos primórdios da institucionalização da Educação Física nas escolas brasileiras, até aquela de terapeuta corporal que alguns lhe imputam nos dias de hoje, passando é claro, pelo papel de técnico desportivo, médico, carpinteiro, pedreiro, pintor, fisioterapeuta, organizador de festas, de fanfarras, de desfiles cívicos etc. etc... e o papel de professor de Educação Física, em que canto se perdeu?

Quanto ao papel do aluno, este é o de figurante no cenário da aula. Ele (aluno) pode ter o papel do recruta que obedece cegamente o instrutor, ou o papel do atleta que "agrada" o técnico, ou o papel de ajudante de pedreiro, carpinteiro, pintor, organizador de festas; pode também desempenhar o papel de paciente do fisioterapeuta, do médico ou do terapeuta corporal.

Há ainda em relação ao papel do aluno, uma forte esteriotipação de papéis sexuais, porque ainda há um forte sexismo ${ }^{15}$ na Educação Física Escolar. As turmas ainda são, em geral, divididas por sexo (até em alguns cursos superiores) e, preferencialmente, ainda é o homem que ministra aulas aos homens e a mulher que ministra aulas às mulheres.

A relação professor e alunos, cada um com seu papel estabelecido, está sujeita a normas e sanções que permitem assim, prever certos limites. As normas e regras, por sua vez, determinam comportamentos adequados para cada um dos papéis em cada situação específica. A disciplina e a ordem formal, portanto, permeiam esta relação, uma vez que, se as regras forem violadas, professores e alunos estão sujeitos a sanções. ...A relação, pois, estabelece-se organicamente a partir dos papéis desempenhados pelos atores e, com certa abstração, pelo indivíduo que está atrás de cada papel. ${ }^{16}$

O desempenho adequado dos papéis, bem como a sua distribuição em diferentes posições só $€$ possivel a partir de um treinamento onde..."todos os atores podem relacionar-se, uma vez que aceitem as mesmas normas sobre os objetivos que buscam e os meios que empregam para alcançá-los."17

O que são nossos cursos de formação onde, via de regra, o questionamento, a crítica, seja de professores, alunos ou funcionários é punido explicitamente ou diluído nas inúmeras estratégias de amortização e abafamento de conflitos? $O$ que são as escolas de 1o. e 20. grau, senão o local onde predomina o silêncio e a conformação com premiação e punição para quem permanece ou sai da norma?

Pautada então em uma concepção mecanicista, num sistema escolar rígido, qual é a possibilidade de um aluno não se tornar um indivíduo autômato, condicionado, um aluno padrão, um homem máquina? ${ }^{18}$

Mesmo com nossa "formação deformada", como podemos recuperar nossa identidade de pessoa consciente e perceber toda a complexidade da problemática educacional em seu conjunto? Que mecanismos deveremos estabelecer para libertar-nos dos condicionamentos reducionistas a das crenças e dogmas que nos tornaram infinidade de coisas mas pouco fizeram para que nos tornássemos professores? 


\section{OUTROS CAMINHOS A PERCORRER...}

Até aqui procuramos fazer um apanhado geral do que tem sido (e ainda 6 ) entendido como função da Educação Física Escolar, e os papéis dos sujeitos concretos da relação pedagógica escolar 0 professor e o aluno.

Cabe-nos agora, eshoçar aquilo que consideramos perspectivas para a Educação Física Escolar, evidenciando, então outras funções, as quais acreditamos não serem "funcionais", mas pelo contrário, desencadeadoras de conflitos e que possam assim, evidenciar as relações de dominação que pesam sobre a instituição escolar e sobre toda a sociedade brasileira. Função agora passa a ser entendida não mais a partir da lógica formal, mas sim da lógica dialética. ${ }^{19}$

Na realidade, analisar e perspectivar outras funções para a Educação Física Escolar, é também buscar a sua legitimidade no interior daquela instituição a partir de outros parâmetros que não aqueles do desenvolvimento da aptidão física com vistas à saúde.

Tentativas neste sentido vem sendo feitas ao longo de toda a década de 80, uma vez que esta década abre para a Educação Física em geral e para a Educação Física Escolar em especial, as possibilidades de estudos a partir não só das ciências da natureza mas também das ciências do Homem.

Neste sentido, cabe registrar aqui os estudos desenvolvidos por Bracht $(1984,1985,1989)$, Carmo (1985), Castellani Filho (1983, 1984, 1988), Cavalcanti (1984), Ferreira (1984), Guiraldelli (1988), Lopes (1979, 1980), Medina (1983), Oliveira, (1983) entre outros, os quais tem trazido elementos necessários para entender os condicionamentos e as determinações que pesaram sobre a Educação Física brasileira e que tem determinado o seu "conteúdo" e a sua "função" na instituição escolar.

Seguindo as análises desenvolvidas por Bracht (1989) acerca da busca de uma autonomia pedagógica para a Educação Física e, portanto, de sua legitimidade no interior da instituição escolar, perguntamos com o autor: "...mas como podemos legitimar a Educação Física na Escola? Em que consiste a importância da Educação Física? Para que serve a Educação Física?" 20

A resposta a estas perguntas, certamente está sendo construída cotidianamente nas milhares de escolas de 10. e 20. graus, bem como através de alguns profissionais nos 105 cursos de Educação Física existentes.

Todavia, consideramos necessário registrar aqui algumas reflexões que vimos fazendo num pequeno grupo, nos últimos anos, em torno da Educação Física Escolar enquanto um componente curricular.

Como já afirmamos em outra oportunidade, 21

...cabe às disciplinas que constituem o currículo (conjunto de atividades nucleares da Escola), transmitir enquanto partes constitutivas de uma totalidade de conhecimentos, o seu particular, sem entretanto, estabelecer uma oposição com o geral. Entretanto, para que possamos realizar esta tarefa, é preciso examinar atentamente o que fundamenta cada disciplina curricular e o porque de sua existência. E preciso captar o que a defíniu como tal, a que necessidade pedagógica veio a atender.

Nas visões por nós analisadas, as necessidades pedagógicas e as funções a serem atendidas e desempenhadas pela Educação Física, limitavam-se ao desenvolvimento da aptidão física com vistas à saúde em sua relação com o mundo da produção: sujeitos mais fortes pelo exercício físico, portanto mais bteis ao trabalho...mais "produtivos."

Bracht $^{22}$ afirma nos dias atuais, ...a Educação Física passa a ser relacionada menos diretamente com o mundo de produção mas de forma mediata através da mediação do lazer, o que em função do maior status social do trabalho (atividade "nobre") em relação ao lazer (atividade "şupérllua") não deixa de construir uma tal dificuldade para tal legitimação. No entanto, o lazer e a educação para o lazer parecem cada vez. mais, serem considerados um tema e uma tarefa também da Escola.

Aponta nesta mesma direção, o documento - "Contribuição ao Debate do Currículo em EDUCAÇÃO FÍSICA: UMA PROPOSTA PARA A ESCOLA PÚBLICA" - elaborado pela Secretaria de Estado da Educação de Pernambuco. ${ }^{23}$ Neste documento, a Educação Física é considerada 
...como uma disciplina que trata, pedagogicamente na escola, alguns "temas" ou "formas" da cultura corporal (...). Os temas ou formas da cultura corporal expressam um sentido e um significado onde se interpretam dialeticamente a intencionalidade/objetivos do homem e as intenções/ob́jetivos da sociedade (...). Desta forma, a Educaçáo Física, no ensino fundamentạl e médio, deverá considerar os aspectos antropologicos da expressão corporal humana, vinculando-se aos princípios da preparação para o mundo do trabalho e da educação para o lazer. Todavia, objetivos, conteúdos e processos metodológicos devem ser analisados à luz dos pressupostos dialéticos da totalidade, da natureza, da história do 39 homem e da elaboraçao de conhecimento.

Compartilhando destas análises e perspectivas é que finalizamos esta nossa intervenção, não sem antes acentuar que a sociedade brasileira necessita de uma radical transformação estrutural, sem a qual nenhuma proposta pedagógica terá êxito.

Isto porque, vivemos num país onde os contrastes se acentuam de modo cada vez mais cruel. A 8a. economia do mundo ocupa o nada confortável 800. lugar em qualidade de vida e possui 8 milhões de menores abandonados, conforme dados divulgados pela Revista Isto É/Senhor no. 1099 de outubro de 1990.

O Documento Base da FAO para o Seminário "Fome, o Desafio dos Anos 90", realizado em São Paulo no mês de outubro de 1990, divulga dados estarrecedores da miséria social no Brasil: são 53 milhões de pessoas que passam fome, ou seja, mais de $\mathbf{4 0 \%}$ da população. Segundo dados do Ministério da Saúde, 840 mil crianças entre 1 e 4 anos e 420 mil recém-nascidos morrerão este ano. São Paulo e Rio de Janeiro juntos tem 4,5 milhões de pessoas que passam fome.

Em São Paulo, o Estado mais rico da Federação, morrem 40.000 crianças com menos de um ano e a expectativa de vida no estado é comparável à do Vietnã, Nicarágua, Tunísia, sendo que a mortalidade infantil é significativamente maior do que naqueles países, segundo Documento elaborado pelo Fórum Estadual de Educação em Defesa da Escola Pública na LDB.

Num dossiê preparado pelo Ministério da Ação Social, a partir de levantamento do Centro Brasileiro para Infância e Adolescência (CBIA), com base em dados tanto da Polícia Federal como em outros, e divulgado pela Folha de São Paulo do dia 25/10/90, existem no Brasil 500 mil menores prostitutas. Com base na população brasileira em 1989 147,4 milhões - existe uma menor prostituta entre cada 300 habitantes.

No Brasil, o salário mínimo, que tem valor quase simbólico, é sequer respeitado. $20 \%$ da população economicamente ativa recebe menos que um salário mínimo. No Estado de São Paulo, 15\% da população economicamente ativa recebe menos de um salário mínimo (Doc. do Fórum est. em Defesa da Escola Pública na LDB).

$70 \%$ da população sobrevive com até três salários mínimos. $80 \%$ dos trabalhadores brasileiros não são filiados a sindicatos ou associações de empregados (Isto E/Senhor no. 1099).

Quanto ao problema do analfabetismo, fator determinante num quadro de miséria social, o Brasil está em sétimo lugar entre os dez países com maior número de analfabetos, lista que é encabeçada pela Índia. São 33 milhões de analfabetos no Brasil, sendo que 5,5 milhōes são crianças com idade entre 7 e 14 anos que ainda não aprenderam a ler. Temos uma evasão escolar de $50 \%$ na primeira série do ensino fundamental e apenas $13 \%$ das crianças que ingressam naquele ensino conseguem concluir os 8 anos de escolaridade (Folha de São Paulo 25/10/90).

Cerca de $20 \%$ da população brasileira com 15 anos ou mais é analfabeta. Em São Paulo, cerca de $15 \%$. Entre a população rural do Brasil o analfabetismo chega a $50 \%$ e no Estado de São Paulo esta taxa é de mais de $20 \%$. Cerca da metade da população trabalhadora em São Paulo tem no máximo 4 anos de escolaridade (Documento do Fórum Estadual em Defesa da Escola Pública na LDB).

Existem ainda inúmeros dados que traduzem a miséria social da $8 \mathrm{a}$. economia do mundo. Finalizamos nossa intervenção com um verso de um poema de $\mathrm{B}$. Brecht ${ }^{24}$ que nos fala sobre a liberdade:

De que serve a liberdade

Se os livres têm que viver entre os não-livres?

...Em vez de serem apenas livres, esforçam-se

Para criar um estado de coisas que liberte a todos

E também o amor à liberdade

Torne supérfluo! 


\section{NOTAS E REFERENCIAS}

1. SILLS, D. L., comp. Enciclopédia Internacional de las Ciências Sociales. Madrid, Aguilar, 1974-1976. v.1, p300.

2. DICIONÁRIO de Ciências Sociais. Rio de Janeiro. Fundação Getúlio Vargas, 1986. p.500.

3. Ibidem, p.501.

4. Ibidem, p.501.

5. Ibidem, p.501.

6. Referimo-nos aqui em especial ao Decreto Federal $n^{0}$ 69.450/71 e ao Parecer 853 do Conselho Federal de Educação que define a Educação Física nos currículos escolares como ATIVIDADE.

7. BRACHT, V. A criança que joga respeita as regras do jogo ..."capitalista" Revista Brasileira de Ciências do Esporte, v.7, n.2, p.62, 1986.

8. Idem, ibidem, p.62.

9. Idem, ibidem, p.62.

10. PARSONS,T., citado por CORREA DA SILVA, N.S.F.. O papel do supervisor no atual contexto brasileiro. Cadernos CEDES, São Paulo, n. 7, p.9, 1983.

11. CORREA DA SILVA, N.S.F., op. cit., p. 9

12. PARSONS, T., citado por CORREA DA SILVA, N.S.F., op. cit., p.10.

13. GOULDNER, A. La crisis de la sociologia occidental. Buenos Aires, Amorrortu, 1979. p.66.

14. Idem, ibidem, p.66.

15. Sobre o assunto consultar DELAMONT, S. Os papéis sexuais e a escola. Lisboa, Horizonte, 1985.

16. CORREA DA SILVA, N.S.F., op. cit., p.8.

17. Idem, ibidem, p.10.

18. Idem, ibidem, p.11.

19. Sobre o assunto consultar: LEFEBVRE, H. Lógica formal e lógica dialética. Rio de Janeiro, Civilização Brasileira, 1983.

20. BRACHT, V. Educação física: a busca da autonomia pedagógica. Revista da Fundação de Esporte e Turismo, Curitiba, v.1, n.2, p.17, 1989.

21. O ESPORTE na escola brasileira. Palestra proferida no 4o. Congresso Brasileiro de Ciências do Esporte, Olinda, PE, 1987.

22. BRACHT, V., op. cit., p.17.

23. PERNAMBUCO. Secretaria de Educação. Contribuição ao debate do currículo em educação física: uma proposta para a Escola Pública. Recife, Secretaria de Educação de Pernambuco, 1989.

24. BRECHT, B. De que serve a bondade? Poemas: 1913-1956. 2.ed. São Paulo, Brasiliense, 1986. 